\title{
Robotic versus laparoscopic splenectomy: a systematic review of perioperative outcomes
}

\author{
Anantha Shreepad Bhat · Alexia Farrugia - Qazi Rahim Muhammad • Viera Kulikova · Gabriele Marangoni · \\ Jawad Ahmad
}

Received: 3 May 2021 / Accepted: 6 May 2021 / Published online: 23 June 2021

(C) The Author(s) 2021

\begin{abstract}
Summary
Background Elective splenectomy has various indications and can be performed open or minimally invasively. Laparoscopic splenectomy (LS) is popular but has limitations. Some studies suggest potential superiority of robotic splenectomy (RS) over LS. As such, we conducted a systematic review to determine whether RS has greater positive perioperative outcomes in comparison to LS in the adult population. Methods We searched for studies that reported perioperative outcomes and compared RS to LS in the adult population. Outcome measures were operative time, conversion to open surgery, postoperative complications, mortality, length of stay, blood loss and cost analysis. A simple, unpaired two-tailed student's t-test was used to compare outcomes between the RS and LS patient groups.

Results After full-text analysis of 47 papers, three studies met the inclusion criteria. The studies involved 72 patients (28 in the RS group, 44 in the LS group). RS demonstrated no significantly reduced blood loss in comparison to LS $(p=0.13)$. RS had no cases con-
\end{abstract}

Supplementary Information The online version of this article (https://doi.org/10.1007/s10353-021-00727-7)

contains supplementary material, which is available to authorized users.

A. S. Bhat · A. Farrugia $\cdot$ G. Marangoni $\cdot$ J. Ahmad $(\bowtie)$

Warwick Medical School, University of Warwick,

Warwick, UK

jawad.ahmad@uhcw.nhs.uk

Q. R. Muhammad ·V. Kulikova · G. Marangoni · J. Ahmad Department of Upper Gastrointestinal and HPB Surgery, University Hospitals Coventry and Warwickshire (UHCW), Clifford Bridge Road, Coventry, CV22DX, UK

\section{A. Farrugia}

Department of General Surgery, Walsall Manor Hospital, Walsall, UK verting to open surgery and no postoperative complications in comparison to LS. No significant difference was found between RS and LS with regards to LOS $(p=0.89)$ and cost benefit $(p=0.74)$. RS had a higher operative time in comparison to LS which was not statistically significant ( $p=0.45)$.

Conclusion The RS approach may be associated with lower blood loss and a lower risk of conversions. There was no statistical difference between RS and LS with regards to length of stay (LOS) and cost. RS takes longer to perform in comparison to LS.

Keywords General surgery · Spleen · Surgical innovation · da Vinci surgical system · Robots

\section{Main novel aspects}

- This study is novel in that it is the first systematic review to compare robotic and laparoscopic perioperative outcomes in solely the adult population

- While acknowledging the historically immense contributions of general surgeons improving perioperative outcomes of both robotic and laparoscopic splenectomies, this study provides a snapshot of the current state of play in the field, while providing definitive suggestions to encourage further studies to compare these surgical modalities in a robust manner.

\section{Introduction}

Elective splenectomy has many indications and can be performed via an open approach or in a minimally invasive manner [1]. Since the inception of laparoscopic splenectomy (LS) [2], improvements of laparoscopic tools for ligation over time have popularised the approach [3]. However, LS does have its limitations, such as a steep learning curve [4]. Multiple 
studies have reported that in difficult operational circumstances such as splenomegaly, obesity, haematological malignancies and previous laparotomies, LS is associated with increased morbidity and conversion rates to open surgery [5-8].

With the introduction and increasing availability of the surgical robot in the operative arena [9, 10], general surgeons are adopting the robotic platform to benefit from its markedly advanced endowristed instruments [11]. While both laparoscopic and robotic surgery are classed as minimally invasive techniques, there are studies which appear to suggest superiority of robotic splenectomy (RS) over the laparoscopic approach [12, 13].

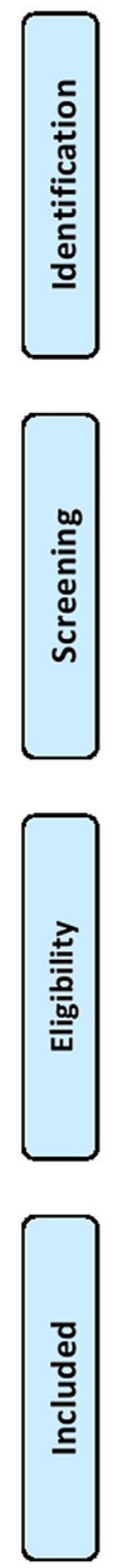

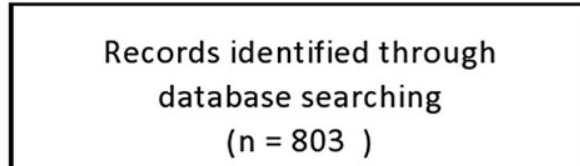

$(n=803)$

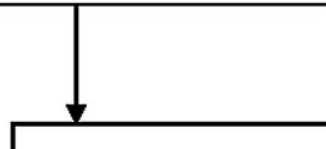

As such, we conducted a systematic review to determine whether RS has greater positive perioperative outcomes in comparison to LS in the adult population.

\section{Material and methods}

\section{Literature search}

This systematic review has been registered on the Prospective Register of Systematic Review Protocols (PROSPERO ID: CRD42020196831). This study adhered to the 'Preferred Reporting Items for Systematic Reviews and Meta-Analysis' (PRISMA) guidelines (Fig. 1). Authors A.S.B. and A.F. independently per-

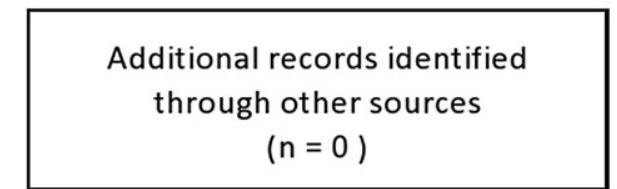

Records after duplicates removed

$(n=535)$
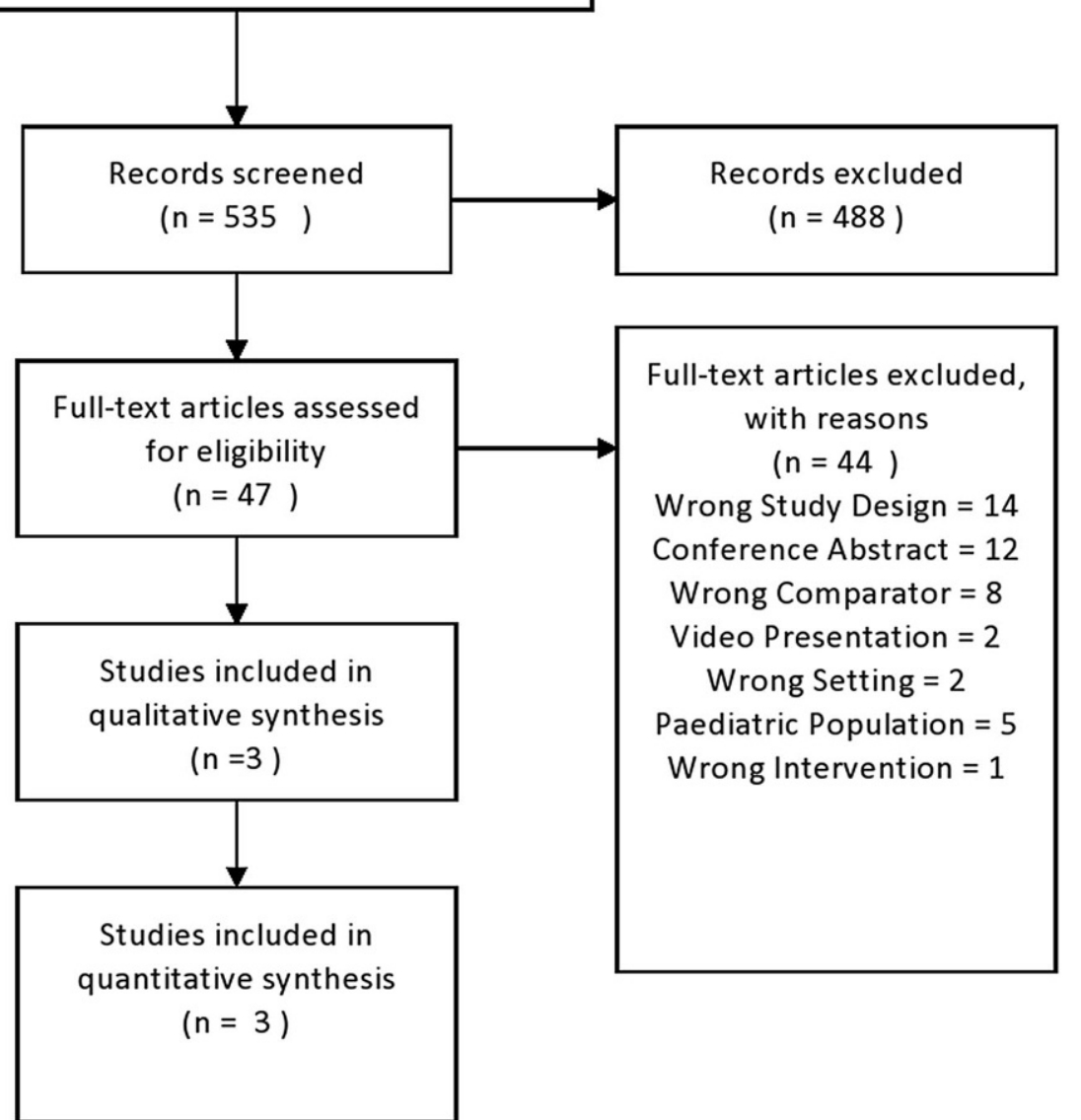

Full-text articles excluded, with reasons

$(n=44)$

Wrong Study Design $=14$

Conference Abstract $=12$

Wrong Comparator $=8$

Video Presentation $=2$

Wrong Setting $=2$

Paediatric Population $=5$

Wrong Intervention $=1$

Fig. 1 PRISMA ${ }^{\circledR}$ flow diagram of the study selection process for systematic review 
formed a literature search using the search engines Embase, PubMed, Web of Science and Cochrane Library for literature that directly compared RS with LS for adult splenectomy procedures where indicated. Search terms employed were the following: robotics, laparoscopic, splenectomy, spleen, surgical procedures. In addition, the reference lists of the included articles were also screened for additional information on the subject matter. There were no language limitations set for this literature search dated up to and including the 31 December 2020.

\section{Inclusion and exclusion criteria}

Inclusion criteria for this study were 1) patients with any indication requiring splenectomy or partial splenectomy; 2) published studies comparing robotic splenectomy (RS) with laparoscopic splenectomy (LS); 3) studies reporting at least one of the following outcomes-operative time, conversion to open, blood loss, hospital stay, cost, postoperative complications, morbidity, mortality; 4) study design-randomised controlled trials (RCTs), cohort studies, observational studies or comparative studies.

Studies meeting the following criteria were excluded: 1) studies showing no comparison between RS and LS; 2) case reports, case series, systematic reviews, conference abstracts, experiments or conference reports; 3) any studies where the full text was unavailable despite contacting the authors; 4) studies that included a paediatric population.

\section{Study selection and data extraction}

Three reviewers (A.S.B., A.F., and V.K.) independently read the full relevant texts and extracted data pertaining to corresponding author, year, country, sponsorship, affiliated institution, population studied, type of surgery, study design, interventions and comparisons, and overall study outcomes. For any studies that were deemed to have missing information regarding these parameters, the authors were contacted via the contact address provided in the text.

\section{Statistical analysis}

To compare quantifiable perioperative parameters between the RS and LS groups, a simple, unpaired twotailed student's t-test was used.

\section{Quality assessment for included studies}

Included studies were assessed for methodological quality by three researchers (A.S.B., A.F., and V.K.) using the widely used and established Newcastle-Ottawa scale (NOS). Parameters such as the selection of study, population and comparability of the groups under study and end outcome assessment were used to score the full texts included. The maximum possible score on the scale is 9 stars. A score $>5$ stars was assigned to a study deemed to have a high methodological quality and low risk of potential bias. Any disagreement between authors was resolved by an agreed consensus.

\section{Results}

There were 47 potential studies that satisfied the inclusion criteria in the initial search (Fig. 1). Of these, we excluded 44 articles with reasoning as follows: 14 due to incorrect study design; 12 were conference $a b-$ stracts; 8 studies used the wrong comparator; 2 studies were video presentations; 2 studies were in the wrong setting; 5 studies consisted of a paediatric population and 1 study used the wrong intervention. For the final systematic review, we included three studies involving a total of 72 patients (28 in the RS group, 44 in the LS group) published between and inclusive of 2005 and 2018.

The characteristics of the three studies are further listed in Table 1. Two of the three studies are RCTs $[14,16]$. The remaining article is a case-control study [15]. All three studies involved conducting a splenectomy. Data obtained from all three included studies are listed in Table 2 and detailed below.

\section{Operative time}

The mean operative time for the RS group was longer in comparison to the LS group; however, this was not statistically significant (182.63 min versus $142.33 \mathrm{~min}$, respectively, $p=0.45$ ). Only one study [15] specifically stated that the same surgeon's expertise was used for conducting both RS and LS procedures.

\section{Conversion to open surgery}

In total, there were 5 LS procedures that were converted to open surgery out of a total of 44 LS procedures across all studies. No RS were converted to an open procedure. Only one study [15] reported no group (RS or LS) having to convert to open surgery.

Table 1 Characteristics of included studies

\begin{tabular}{|l|l|l|l|l|l|l|l|}
\hline References & Year & Country & Study design & Surgery types & Total sample size & Robotic & Laparoscopic \\
\hline Cavaliere et al. [14] & 2018 & Italy & Retrospective cohort & Robotic vs. laparoscopic splenectomy & 39 & 12 \\
\hline Bodner et al. [15] & 2005 & Austria & Case-control & Robotic vs. laparoscopic splenectomy & 12 & 27 \\
\hline Belravichus et al. [16] & 2015 & Russia & Retrospective cohort & Robotic vs. laparoscopic splenectomy & 21 & 6 \\
\hline
\end{tabular}


Table 2 Summary of perioperative outcomes included in the study analysis. Raw values reported in the respective studies are presented

\begin{tabular}{|c|c|c|c|c|c|c|c|c|c|}
\hline Article & Group & $\begin{array}{l}\text { Operative time } \\
\text { (mins) }\end{array}$ & $\begin{array}{l}\text { Conversion to } \\
\text { open surgery } \\
\text { (number) }\end{array}$ & $\begin{array}{l}\text { Postoperative } \\
\text { complications } \\
\text { (number) }\end{array}$ & $\begin{array}{l}\text { Mortality } \\
\text { (number) }\end{array}$ & $\begin{array}{l}\text { Length of } \\
\text { stay (days) }\end{array}$ & $\begin{array}{l}\text { Blood loss } \\
(\mathrm{mL})\end{array}$ & Cost (\$USD) & $\begin{array}{l}\text { Time taken to insert tro- } \\
\text { cars and establish pneu- } \\
\text { moperitoneum (min) }\end{array}$ \\
\hline \multirow{2}{*}{$\begin{array}{l}\text { Cavaliere et al. } \\
\text { [14] }\end{array}$} & LS & 180 & 4 & 3 & 1 & 6 & $\mathrm{~N} / \mathrm{A}$ & $\mathrm{N} / \mathrm{A}$ & N/A \\
\hline & RS & 270 & 0 & 0 & 0 & 6 & $\mathrm{~N} / \mathrm{A}$ & N/A & $\mathrm{N} / \mathrm{A}$ \\
\hline \multirow{2}{*}{$\begin{array}{l}\text { Bodner et al. } \\
\text { [15] }\end{array}$} & LS & 127 & 0 & 0 & 0 & 6 & 350 & 4084 & 10 \\
\hline & RS & 154 & 0 & 0 & 0 & 7 & 100 & 6927 & 26 \\
\hline \multirow[t]{2}{*}{$\begin{array}{l}\text { Belravichus } \\
\text { et al. [16] }\end{array}$} & LS & $120 \pm 57.8$ & 1 & 2 & 0 & 7.8 & $215 \pm 268.8$ & $\begin{array}{l}580.50 \text { (43,000 } \\
\text { Russian Rubles) }\end{array}$ & $\mathrm{N} / \mathrm{A}$ \\
\hline & RS & $123.9 \pm 39.8$ & 0 & 0 & 0 & 7.1 & $122.2 \pm 257$ & $\begin{array}{l}526.50 \text { ( } 39,000 \\
\text { Russian Rubles) }\end{array}$ & $\mathrm{N} / \mathrm{A}$ \\
\hline
\end{tabular}

Table 3 Further breakdown of postoperative complications using the Clavien-Dindo classification

\begin{tabular}{|c|c|c|c|}
\hline Article & Group & $\begin{array}{l}\text { Total number of } \\
\text { postoperative com- } \\
\text { plications }\end{array}$ & $\begin{array}{l}\text { Breakdown of Clavien-Dindo clas- } \\
\text { sification per individual patient } \\
\text { case }\end{array}$ \\
\hline \multirow{2}{*}{$\begin{array}{l}\text { Cavaliere } \\
\text { et al. [14] }\end{array}$} & LS & 3 & 2 grade $I I, 1$ grade IV \\
\hline & RS & 0 & N/A \\
\hline \multirow{2}{*}{$\begin{array}{l}\text { Belravichus } \\
\text { et al. [16] }\end{array}$} & LS & 2 & 2 grade IV \\
\hline & RS & 0 & $\mathrm{~N} / \mathrm{A}$ \\
\hline
\end{tabular}

\section{Postoperative complications}

The RS group reported no postoperative complications. In total, 5 LS procedures involved postoperative complications. Observing a further breakdown of the Clavien-Dindo classification per individual patient case (Table 3), the LS group in [14] reported two grade II complications (one retroperitoneal haematoma and one postoperative pneumonia) and one grade IV complication (one re-operated for massive hemoperitoneum on the first operative day and died $24 \mathrm{~h}$ later due to multiple organ failure). The LS group in [16] reported two grade IV complications (one left-sided hydrothorax and one postoperative collection in the region of the edge of the resected spleen).

\section{Mortality}

Only one study [14] reported a single case of mortality which belonged to the LS group. The remaining studies $[15,16]$ reported no mortality for the RS and LS groups.

\section{Length of stay}

Mean LOS was not significantly different between RS and LS groups (6.7 days versus 6.6 days, respectively, $p=0.89$ ).

\section{Blood loss}

Two studies $[15,16]$ reported blood loss. Of these studies, the mean blood loss of the RS group was lower in comparison to the LS group, although this was not statistically significant $(111.1 \mathrm{ml}$ versus $282.5 \mathrm{ml}$, respectively, $p=0.13$ ).

\section{Cost analysis}

Two studies [15, 16] reported average costs for both the RS and LS procedural groups. Costs were reported in US Dollars (USD) and Russian Rubles, respectively. Bodner et al. reported a higher cost for the RS group in comparison to the LS group (\$6927 USD versus \$4084 USD, respectively), while Belravichus et al., reported the RS group to be more cost effective in comparison to the LS group ( $\$ 526.50$ USD versus $\$ 580.50$ USD rough equivalent using present day exchange rates). There was no significant difference between LS and RS groups $(p=0.74)$.

\section{Additional perioperative outcomes}

Only one study [15] reported the time taken to insert trocars and establish pneumoperitoneum. The findings reported the RS group achieving this outcome within an average of $26 \mathrm{~min}$, while the LS group managed it within an average of $10 \mathrm{~min}$.

\section{Bias assessment}

The Newcastle-Ottawa scale (Supplementary Table 1) was used to assess bias in these studies due to their study design. This showed that all included studies [14-16] scored 8 stars out of a possible 9 stars and thus had a low risk of potential bias.

\section{Discussion}

This study highlighted RS to have reduced blood loss in comparison to LS $[15,16]$. In particularly difficult cases involving malignant hemopathies, splenic tumours, partial splenectomy and splenectomy in liver cirrhosis, the RS approach may prove to be potent for decreasing the risk of haemorrhagic complications during surgery and performing minimally invasive splenectomy where the LS approach has proven to be very difficult [17]. 
The RS approach was reported to have no patient cases converting to open surgery and no postoperative complications or mortality in comparison to LS. In addition to these findings, breakdown of the postoperative complications revealed that a larger proportion of postoperative LS complications were classed as grade IV $[14,16]$. These findings are largely consistent with a recent meta-analysis comparing RS and LS in the surgical management of non-traumatic diseases of the spleen. The study showed RS to have both significantly lower conversion rates to open surgery and postoperative complications in comparison to LS. Perioperative mortality was not observed in the RS group [18].

We found no significant difference in LOS in the three studies that were compared. One study based in Austria [15] attributed similar and relatively longer LOS for both RS and LS due to less pressure from insurance companies in comparison to the United States. In this regard, previous research of the US healthcare system has elucidated nonclinical factors such as race, education, gender and socioeconomic status to be associated with patients being uninsured and experiencing a longer LOS [19]. We can provide two counter arguments validating shorter LOS. The first is that a prolonged LOS has the potential to deny healthcare access to critically ill patients to timely access to treatment. The second is that patients with prolonged LOS are also at a higher risk of developing nosocomial infections and subsequent unplanned hospital readmissions, which, in turn, disadvantages both patients and hospitals alike [20,21].

Another important issue raised when comparing RS and LS modalities is cost analysis. Our findings indicated that there was no significant procedural cost difference between the two approaches [15, 16]. It is important to consider that in the two studies that reported this parameter, the currencies used to calculate the total costs for the procedures were not the same, making it difficult to comparatively analyse the cost benefits of both RS and LS. In addition to this, there are currently only two studies comparing the costs in US dollars between RS and LS, which involve both adult and paediatric populations. Both studies concluded that while RS is more expensive than LS, it is feasible [22, 23].

Our study found RS to have an increased operative time in comparison to LS. It is likely that the published series on RS are from the early adopters of robotic surgery, hence the longer operating times. Setting up and docking the robot adds time to the procedure. Finally, most robotic surgeons would agree that due to the $3 \mathrm{D}-\mathrm{HD} \times 10$ magnified view, they see more unnamed blood vessels and to secure these with clips requires frequent instrument exchanges which adds time to the surgery. Hopefully, with the introduction of advanced energy devices (e.g., SynchroSeal ${ }^{\circledR}$ Intuitive Surgical), operating times will improve.
A retrospective cohort study by Giza et al. compared RS and LS approaches and was conducted over a span of 17 years [24]. In this study, patients were assigned via a scoring system to one of two groups-simple or complex, according to the degree of surgical complexity. The researchers found that for complex, difficult splenectomies, the robotic system was significantly beneficial. Further studies that stratify splenectomy procedures according to surgical complexity will enhance our understanding of the role of RS in complex procedures.

Our study is significant in that it evaluates the perioperative parameters involved in both RS and LS. However, there are a few limitations to our findings. First, many articles were excluded from our systemic search because they focussed on surgeries other than minimally invasive splenectomies. Second, there was heterogeneity in our results due to the limited number of articles that were analysed that satisfied our inclusion criteria. Third, due to the limited adult patient volume analysed in this study, the power of our findings is relatively low. Fourth, this study could not analyse the long-term outcomes of both RS and LS due to lack of data. We must also mention the possibility of selection bias in the robotic group, as in most cases this was a novel procedure.

In conclusion, our systematic review has shown that RS was associated with lower blood loss, a lower risk of conversion to open surgery and fewer postoperative complications. However, there was no significant difference between RS and LS in terms of LOS and cost benefit. Lastly, RS had a higher intraoperative time in comparison to LS. While these findings are encouraging in favour of RS, it is important to emphasise that further larger-scale comparison studies are required to be conclusive.

Acknowledgements The authors would like to thank Samantha Johnson from Warwick Medical School for her assistance in developing the search strategy and providing the necessary training to use the incorporated search engines.

Funding Open access funding provided by University of Warwick.

Conflict of interest A.S. Bhat, A. Farrugia, Q. R. Muhammad, V. Kulikova, G. Marangoni and J. Ahmad declare that they have no competing interests.

Ethical approval This study did not require ethical approval from the institutional review board (IRB) and written consent.

Open Access This article is licensed under a Creative Commons Attribution 4.0 International License, which permits use, sharing, adaptation, distribution and reproduction in any medium or format, as long as you give appropriate credit to the original author(s) and the source, provide a link to the Creative Commons licence, and indicate if changes were made. The images or other third party material in this article are included in the article's Creative Commons licence, unless indicated otherwise in a credit line to the material. If material is not included in the article's Creative Commons licence and your intended use is not permitted by statutory regulation or 
exceeds the permitted use, you will need to obtain permission directly from the copyright holder. To view a copy of this licence, visit http://creativecommons.org/licenses/by/4.0/.

\section{References}

1. Katz SC, Pachter HL. Indications for splenectomy. Am Surg. 2006;72:565-80.

2. DelaitreB, Maignien B.Laparoscopicsplenectomy-technical aspects. Surg Endosc. 1992;6:305-8.

3. Misiakos EP, Bagias G, Liakakos T, Machairas A. Laparoscopic splenectomy: current concepts. World J Gastrointest Endosc. 2017;9(9):428-37.

4. Bagdasarian RW, Bolton JS, Bowden JC, Fuhrman GM, Richardson WS. Steep learning curve of laparoscopic splenectomy. J Laparoendosc Adv Surg Tech. 2009;10(6): 319-23.

5. Corcione F, Pirozzi F, Aragiusto G, Galante F, Sciuto A. Laparoscopic splenectomy: experience of a single center in a series of 300 cases. Surg Endosc. 2012;26(10):2870-6.

6. Moris D, Dimitriou N, Griniastos J. Laparoscopic splenectomy for benign hematological disorders in adults: a systematic review. In Vivo. 2017;31(3):291-302.

7. Patel AG, Parker JE, Wallwork B, Kau KB, Donaldson N, Rhodes MR, et al. Massive splenomegaly is associated with significant morbidity after laparoscopic splenectomy. Ann Surg. 2003;238(2):235-40.

8. Wysocki M, Radkowiak D, Zychowicz A, Rubinkiewicz M, Kulawik J, Major P, et al. Prediction of technical difficulties in laparoscopic splenectomy and analysis of risk factors for postoperative complications in 468 cases. J Clin Med. 2018;7(547):1-11.

9. Lane T. A short history of robotic surgery. Ann R Coll Surg Engl. 2018;100(6):5-7.

10. Sheetz KH, Claflin J, Dimick JB. Trends in the adoption of robotic surgery for common surgical procedures. JAMA NetwOpen. 2020;3(1):1-9.

11. Szold A, Bergamaschi R, Broeders I, Dankelman J, Forgione A, Lango T, et al. European association of endoscopic surgeons (EAES) consensus statement on the use of robotics in general surgery. Surg Endosc. 2015;29:253-88.

12. Hanly EJ, Talamini MA. Robotic abdominal surgery. Am J Surg. 2004;188:19S-22S

13. Casaccia M, Stabilini C, Gianetta E, Ibatici A, Santori G. Current concepts of laparoscopic splenectomy in elective patients. World J Surg Proced. 2014;4(2):33-47.
14. Cavaliere D, Solaini L, Pietrantonio DD, D'Acapito F, Tauceri F, Framarini M, et al. Robotic vs laparoscopic splenectomy for splenomegaly: a retrospective comparative cohort study. Int JSurg. 2018;55:1-4.

15. Bodner J, Kafka-Ritsch R, Lucciarini P, Fish JH, Schmid T. A critical comparison of robotic versus conventional laparoscopic splenectomies. World J Surg. 2005;29:982-6.

16. Berelavichus S, SmirnovA, Ionkin D, Krieger A, Dugarova R. Robot-assisted and laparoscopic partial splenectomy for nonparasitic cysts. Khirurgiia. 2015;7:41-8.

17. Vasilescu C, Stanciulea O, Tudor S. Laparoscopic versus robotic subtotal splenectomy in hereditary spherocytosis. Potential advantages and limits of an expensive approach. Surg Endosc. 2012;26(10):2802-9.

18. Peng F, Lai L, Luo M, Su S, Zhang M, He K, et al. Comparison of early postoperative results between robot-assisted and laparoscopic splenectomy for non-traumatic splenic diseases rather than portal hypertensive hypersplenism - a meta-analysis. Asian J Surg. 2020;43:36-43.

19. Englum BR, Hui X, Zogg CK, Chaudhary MA, Villegas C, Bolorunduro OB, et al. Association between insurance status and hospital length of stay following trauma. Am Surg. 2016;82(3):281-8.

20. Lee SY, Lee S-H, Tan JHH, Foo HSL, Phan PH, Kow AWC, et al. Factors associated with prolonged length of stay for elective hepatobiliary and neurosurgery patients: a retrospective medical record review. BMC Health Serv Res. 2018;18(5):1-9.

21. Freitas A, Silva-Costa T, Lopez F, Garcia-Lema I, TeixeiraPinto A, Brazdil P, et al. Factors influencing hospital length of stay outliers. BMCHealth Serv Res. 2012;12(265):1-10.

22. Gelmini R, Franzoni C, Spaziani A, Patriti A, Casciola L, Saviono M. Laparoscopic splenectomy: conventional versus robotic approach - a comparative study. J Laparoendosc Adv Surg Tech A. 2011;21(5):393-8.

23. Giulianotti P, Buchs N, Addeo P, Ayloo S, Bianco F. Robotassisted partial and total splenectomy. Int J Med Robot. 2011;7(4):482-8.

24. Giza D-E, Tudor S, Purnichescu-Purtan RR, Vasilescu C. Robotic splenectomy: what is the real benefit? World J Surg. 2014;38:3067-73.

Publisher's Note Springer Nature remains neutral with regard to jurisdictional claims in published maps and institutional affiliations. 